Article

\title{
Leaf Response to Different Light Spectrum Compositions during Micropropagation of Gerbera Axillary Shoots
}

\author{
Monika Cioć * (D) and Bożena Pawłowska \\ Department of Ornamental Plants and Garden Art, University of Agriculture in Krakow, 29 Listopada 54, \\ 31-425 Kraków, Poland; bozena.pawlowska@urk.edu.pl \\ * Correspondence: monika.cioc@urk.edu.pl; Tel.: +48-12-662-5245
}

Received: 27 October 2020; Accepted: 20 November 2020; Published: 22 November 2020

\begin{abstract}
The experiment evaluated the influence of different light qualities and 6-benzyladenine (BA) concentration in a medium on the leaf response of multiplied Gerbera jamesonii Bolus ex Hook. f.'Big Apple' shoots. Three different light-emitting diode (LED) spectra-100\% blue (B), 100\% red (R) and red and blue mixture (7:3, RB)—were used, and a fluorescent lamp was used as a control (Fl). Concentrations of BA in Murashige and Skoog (MS) medium were 1, 2.5 and $5 \mu \mathrm{M}$. Leaves developed under $100 \%$ blue light had a lower frequency of stomata and a smaller area as compared with those from plants exposed to light with red in spectrum. Under 100\% red light, the leaf area and the frequency of stomata increased along with growing concentration of BA in the medium. The thickest mesophyll was spotted in the cross-section of leaves exposed to the blue LED light. Leaves developed under the $100 \%$ red light had the thinnest mesophyll layers. Increasing concentration of BA in the medium resulted in enhanced leaf blade thickness. The cross-section of leaf vascular bundles was only half of that in petioles. The leaves under the LED combinations had larger vascular bundles than those under fluorescent light. The highest level of photosynthetic pigments was noticed in the leaves grown under LED R and RB lights. Our study demonstrated that $2.5 \mu \mathrm{M}$ BA and a mixture of blue and red light provided by LED improved leaf quality during multiplication of gerbera shoots.
\end{abstract}

Keywords: LED; light quality; anatomical structure; stomata; photosynthetic pigments; BA concentration; in vitro

\section{Introduction}

Plants cultivated in vitro have limited photosynthetic abilities, which is why light exerts the greatest effect on morphogenesis under these conditions. External factors of a culture, mainly the spectral quality of light and growth regulators in the medium, affect plant growth and development in vitro. Plant response manifests itself not only in external morphological changes at every stage of clonal propagation but also at the anatomical level. Leaves show high phenotypic plasticity as a response to light conditions and the modifications are easier to observe than those in stems or roots [1]. The light inside the leaf passes through the palisade and spongy mesophyll [2]. In tissue cultures, the epidermis and other tissue layers are often less developed and thinner than in traditionally cultivated plants, as the humidity inside the vessels is relatively high. As a result, plants experience huge water loss during acclimatization, which is the reason for their reduced effectiveness of adaptation to ex vitro conditions. Evaluation of structural changes in a tissue or organ formed in vitro is of great value in establishing the actual efficiency of organogenesis and the functioning of new organs, such as leaves [3]. The anatomical structure of a leaf, affected, e.g., by the external light environment, affects the leaf internal light environment. Many parts of a leaf can absorb light at different wavelengths-for example, 
leaf pigments mainly absorb light in the visible wavelength range $(400-700 \mathrm{~nm})$ and the water present in the cells absorbs light in the infrared range (1400-2500 nm). The spectrum of the light inside the leaf is gradually limited. For example, green light is less absorbed by chlorophyll than blue and red light, and as a consequence, more green light reaches the lower layers of the leaf [4].

Thanks to bicellular structures-stomata-plants can respond and adapt to the conditions of the external environment [5]. The spectral composition of light is a stimulus perceived as a signal and it controls the opening and closing of stomata [6]. Blue light, recognized by phototropins found in guard cells, is particularly important for this process in in vitro cultures. Stomatal opening is triggered by the activation of a plasma membrane pump. The blue-light-activated pump provides the energy needed to open the stomata and to accumulate ions and expand the guard cells [7]. However, in addition to the micropore opening, the spectral quality of light also shapes the developmental parameters of stomata, such as their number, length or width [8]. The stomata form as a result of an asymmetric division of the meristemoid mother cell, which produces a meristemoid, a stem-cell-like triangular cell, and a larger sister cell. Then, the meristemoid can undergo up to three asymmetric divisions or differentiate into a round guard mother cell, a symmetric division of which generates a pair of guard cells forming a stoma. The larger sister cell may undergo further asymmetric divisions and generate satellite meristemoids, usually avoiding contact between new and existing stoma, or it may eventually differentiate into an epidermal cell. The stomatal development is also affected by other environmental factors, such as the presence of growth regulators in the medium [9]. Depending on the used plant regulator, there may be a different number of stomata in in vitro cultures. Changes may also concern uniform distribution, shape and structure of stomata cells [10].

Plant response to different light qualities is manifested in the internal structure of leaves. The study involved the leaves of Gerbera jamesonii obtained using an efficient micropropagation protocol [11-13]. This allowed to assess the effect of light quality and 6-benzyladenine (BA) presence in the medium on various parameters of the leaf, i.e., frequency and size of stomata, anatomical structure of leaf blade and petiole and photosynthetic pigments level.

Gerbera leaf mesophyll has a diversified structure. The palisade mesophyll is located in the upper part and the spongy mesophyll in the lower part of the blade. The anatomical structure of gerbera leaves grown in vitro differs from that in the leaves grown in a traditional way. In vitro leaves develop no collenchyma, the palisade mesophyll is less diverse and the spongy mesophyll has fewer cell layers. The upper and lower epidermis consists of only one layer of cells and is thinner than in traditionally cultivated plants [3].

The aim of the experiment was to investigate the influence of external factors in an in vitro culture conditions-different light-emitting diode (LED) light qualities and BA concentrations in the medium and their interactions-on leaf response during multiplication of gerbera shoots.

\section{Materials and Methods}

\subsection{Plant Material and Growth Conditions}

The study involved leaves of axillary shoots of Gerbera jamesonii Bolus ex Hook. f. cv. Big Apple, multiplied in vitro in Murashige and Skoog (MS) medium [14], supplemented with $30 \mathrm{~g} \cdot \mathrm{dm}^{-3}$ sucrose, solidified with 0.5\% BioAgar (Biocorp, Warsaw, Poland) at $\mathrm{pH}$ 5.7.

The medium was enriched with 1-naphthaleneacetic acid (NAA) and 6-benzyladenine (BA). The cytokinin was tested at three concentrations: 1, 2.5 and $5 \mu \mathrm{M}$ (Duchefa Biochemie, Haarlem, the Netherlands). Shoot multiplication was conducted in glass jars covered with polyvinyl chloride caps with an air orifice (MZ Forma, Łódź, Poland). The conditions in a growth chamber were as follows: $16 / 8 \mathrm{~h}$ photoperiod (day/night), temperature of $23 / 21 \pm 1{ }^{\circ} \mathrm{C}$ (day/night) and $80 \%$ relative humidity.

The second experimental factor was light of different qualities provided by light-emitting diodes (three combinations): $100 \%$ red light $(670 \mathrm{~nm})(\mathrm{R}), 100 \%$ blue light $(430 \mathrm{~nm})(\mathrm{B})$ and a mixture of red and blue light (7:3) (RB). Parameters were provided by a solid-state lighting (light-emitting diodes) system 
(SSL LED) and were set using a BTS256 spectrometer (Gigahertz-Optik, Türkenfeld, Germany) and a LI-250A light meter equipped with a Q 50,604 sensor (LI-COR, Lincoln, NE, USA). The settings were controlled using the DXM-512 digital protocol [11]. The control was a fluorescent lamp (Philips TK-D 36W/54). For all tested light qualities, photosynthetic photon flux density (PPFD) was $35 \mu \mathrm{mol} \mathrm{m}{ }^{-2} \mathrm{~s}^{-1}$.

The culture of multiplied shoots involved five repetitions per treatment, with five explants each (in total, 300 explants). After six weeks of shoot multiplication for analysis of stomata features, anatomical structure and photosynthetic pigments level, leaves were collected with the exception of the youngest and the oldest ones. Stomata analysis involved 100 random leaves, using which we performed 72 epidermal imprints (six representative samples from each treatment combination). Leaf anatomy analysis covered a total of 240 representative samples (10 from each combination for both the blade and the petiole). The content of photosynthetic pigments was assessed in a total of 48 samples from all combination treatments.

\subsection{Data Collection and Analysis}

In order to assess stomata frequency on the surface of the abaxial leaf blade as well as stomata size and the degree of stomata opening (width and length of the pore), microscopic preparations were made using the epidermal imprint method [15]. Preparations were observed under an Axio Observer inverted microscope (Carl Zeiss, Jena, Germany). To count the number of stomata (stomata frequency), microscopic photographs were taken under 20x magnification, and the observable area was $500 \times 500 \mu \mathrm{m}$. To measure the area, width and length of the stomata, and width and length of the pore, microscopic photographs were taken under 40x magnification (Figure 1a).
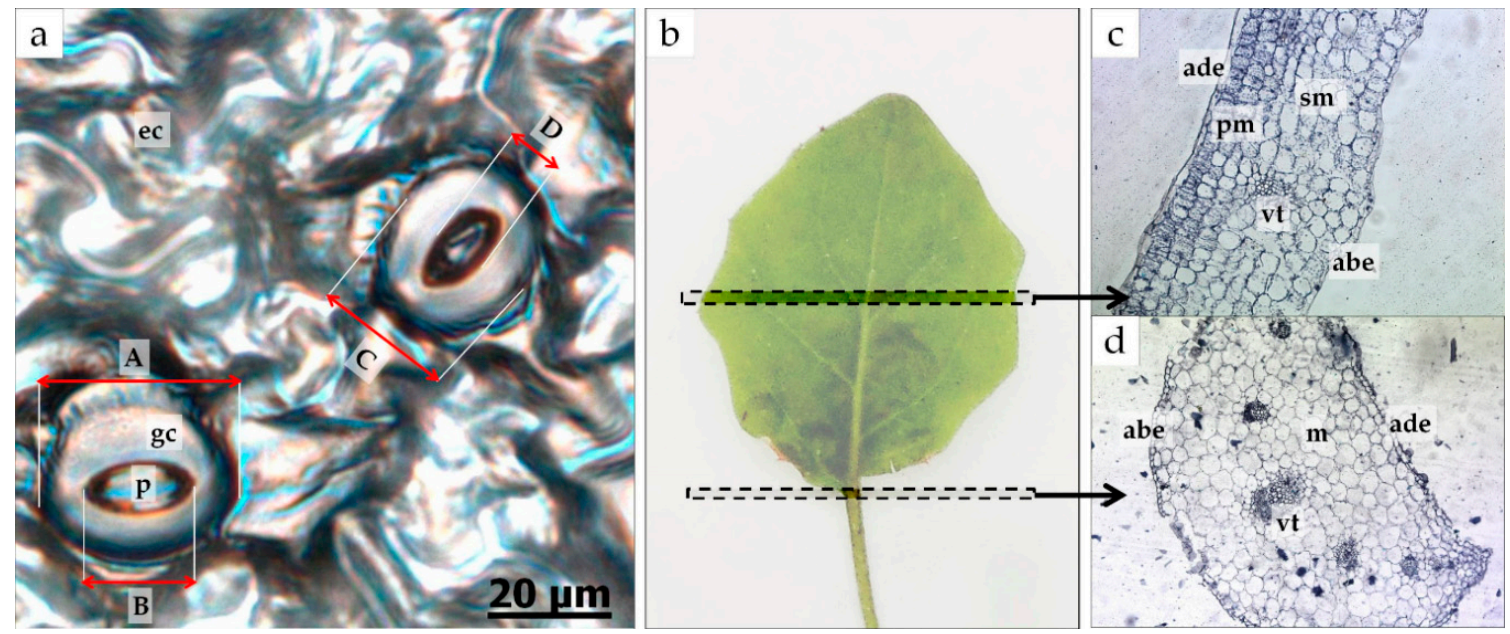

Figure 1. Leaf analysis: (a) stomata measurements-A, stomata length; B, pore length; C, stomata width; D, pore width. Abbreviations: ec—epidermal cells; gc—guard cells; p-pore. (b) The site of sample collection for anatomical cross-section analysis-A, leaf blade; B, leaf petiole. (c) Anatomical cross-section of the blade and (d) petiole; ade-adaxial epidermis; pm-palisade mesophyll; sm—spongy mesophyll; vt—vascular bundles; abe—abaxial epidermis.

To examine leaf anatomy, the paraffin preparation method [16] involving leaf cross-sections was used. In this method, the collected plant material, cut from the central part of the leaf blade and a part of the petiole (Figure 1b), was fixed in Carnoy's solution (60\% ethanol, $30 \%$ chloroform and $10 \%$ glacial acetic acid) overnight. Then, it was dehydrated in a graded alcohol series, followed by embedding in paraffin (stored at $60^{\circ} \mathrm{C}$ for a month). Eosin was used for tissue staining. The samples embedded in paraffin were formed into blocks. They were then cut into semithin sections to obtain permanent microscopic slides. The rotary microtome (Microm HM 325) was used. The samples were stained with hematoxylin and fixed in Canadian balsam. Microscopic observations were made under an Axio Observer inverted microscope (Carl Zeiss). Microscopic images were captured using an AxioCam 
MRc5, 60NC 2/3"camera, $0.63 \times$ (Zeiss). A 20x magnification was used to measure the thickness of the entire cross-section, of the upper and lower epidermis and of the spongy and palisade mesophyll and the width and length of the vascular bundles of the leaf blade (Figure 1c-d). A 10x magnification was used for the petioles. The petiole measurements involved total leaf petiole thickness, thickness of the upper and lower epidermis and the width and length of vascular bundles on cross-sections.

To determine the level of photosynthetic pigments, the spectrophotometric method by Lichtenthaler and Buschmann [17] was used. Tissue samples of 200-mg fresh weight from the collected plant material (leaf blades of moderate age) were dissolved in $80 \%$ acetone. The absorbance was measured at the following wavelengths $(\lambda \max )$ with a Helios Alpha UV/VIS spectrophotometer (Unicam Ltd., Cambridge, Great Britain) to determine chlorophyll $a, b$ and carotenoid contents: chlorophyll $a-663.2 \mathrm{~nm}$; chlorophyll $b-646.8 \mathrm{~nm}$; carotenoids $-470 \mathrm{~nm}$. The contents of photosynthetic pigments were calculated using equations of the method: chlorophyll $a\left(c_{a}\right)(\mu \mathrm{g} / \mathrm{mL})=12.25 A_{663.2}-2.79 A_{646.8}$, chlorophyll $b\left(c_{b}\right)(\mu \mathrm{g} / \mathrm{mL})=21.50 A_{646.8}-5.10 A_{663.2}$, carotenoids $(\mu \mathrm{g} / \mathrm{mL})=\left(1000 A_{470}-1.82 c_{a}-\right.$ $\left.85.02 c_{b}\right) / 198$ (where $A$ is the absorption level).

\subsection{Statistical Analysis}

All collected data were subjected to statistical analysis using Statistica software version 13 (TIBCO Software Inc., Palo Alto, CA, USA). The effects of the treatments were tested for significance using an analysis of variance (ANOVA). The effects of light quality, BA content and the interactions between them were evaluated at two levels of significance: $p \leq 0.05$ and $p \leq 0.01$. The Duncan post hoc multiple range test was used to separate significantly different means and to provide homogeneous groups for the means (at $p \leq 0.05$ ). Additionally, a correlation analysis was performed to determine the strength of relationships between photosynthetic pigment content and anatomical features (stomata features and leaf cross-sections).

\section{Results}

Treatments with lights of different qualities and BA concentrations influenced the assessed parameters of the gerbera leaves (Table 1). Different light qualities applied during in vitro shoot multiplication of gerbera changed the thickness of leaf blades and petioles (except for width of vascular bundles) and the level of photosynthetic pigments. Light spectrum also considerably affected the stomata frequency on the abaxial epidermis, their area and width. Different BA concentrations influenced the length and width of stomata (and pore) and the thickness of tissues measured in the leaf cross-section. The two-factor analysis showed significant differences in stomatal features and anatomical structure and no differences in the level of photosynthetic pigments.

Table 1. Significant impact of light quality and 6-benzyladenine (BA) concentration in the medium and their interactions on the measured parameters of gerbera leaves grown in vitro.

\begin{tabular}{cccc}
\hline Main Effects: & Light Quality $\times$ BA & Light Quality & BA \\
\hline Stomata features & & & \\
\hline Stomata frequency & $* * * 1$ & $* * *$ & n.s. \\
Stomata area & $* * * * *$ & n.s. \\
Stomata length & $* * *$ & n.s. & n.s. \\
Stomata width & $* * *$ & $* * *$ & $* *$ \\
Pore length & $* * *$ & n.s. & $* *$ \\
Pore width & $* * *$ & $* * *$ & \\
\hline & Anatomical structure of blade & & $* * *$ \\
Total thickness & $* * *$ & $* * *$ & n.s. \\
Adaxial epidermis & $* * *$ & $* * *$ & \\
Abaxial epidermis & n.s. & $* * *$ &
\end{tabular}


Table 1. Cont.

\begin{tabular}{|c|c|c|c|}
\hline Main Effects: & Light Quality $\times$ BA & Light Quality & BA \\
\hline Palisade mesophyll & $* * *$ & $* * *$ & $* * *$ \\
\hline Spongy mesophyll & $* * *$ & $* * *$ & $* * *$ \\
\hline Vascular bundles width & $* *$ & $* * *$ & $* * *$ \\
\hline Vascular bundles height & n.s. & $* * *$ & $* * *$ \\
\hline \multicolumn{4}{|c|}{ Anatomical structure of petiole } \\
\hline Total thickness & $* * *$ & $* * *$ & $* *$ \\
\hline Adaxial epidermis & $* * *$ & $* * *$ & n.s. \\
\hline Abaxial epidermis & $* * *$ & $* * *$ & $* * *$ \\
\hline Vascular tissues width & $* * *$ & n.s. & $* * *$ \\
\hline Vascular tissues height & $* * *$ & $* * *$ & n.s. \\
\hline \multicolumn{4}{|c|}{ Photosynthetic pigments level } \\
\hline Chlorophyll $a$ & n.s. & $* * *$ & n.s. \\
\hline Chlorophyll $b$ & n.s. & $* * *$ & n.s. \\
\hline Carotenoids & n.s. & $* * *$ & n.s. \\
\hline
\end{tabular}

\subsection{Stomata Features}

Blue light $(100 \%$ B) reduced the stomata frequency on the abaxial side of the leaf blade as compared with the other light qualities (Figure 2, Table 2). When a red band (R, RB, Fl) was present in the light spectrum, the leaves developed greater stomata frequency. In addition, in the leaves of plants grown under the fluorescent control light (Fl), the stomata had a smaller area than those formed under the other light combinations (Table 2). Increased area of the stomata was observed in the plants multiplied under $100 \%$ blue or $100 \%$ red light. All the light spectra emitted by the LEDs, especially $100 \%$ red light, enhanced the width of the pores but had no effect on their length.

Table 2. Characteristics of the stomata in gerbera leaves after 6 weeks of in vitro cultivation of shoots depending on the quality of light and the concentration of BA in the medium.

\begin{tabular}{|c|c|c|c|c|c|c|}
\hline \multirow{2}{*}{ Tested Feature } & \multicolumn{4}{|c|}{ Stomata } & \multicolumn{2}{|c|}{ Pore } \\
\hline & Mean Number & Area $\left(\mu \mathrm{m}^{2}\right)$ & Length $(\mu \mathrm{m})$ & Width $(\mu \mathrm{m})$ & Length $(\mu \mathrm{m})$ & Width $(\mu \mathrm{m})$ \\
\hline \multicolumn{7}{|c|}{ Light quality } \\
\hline $\mathrm{B}^{1}$ & $22.00 \pm 4.64 \mathrm{a}^{2}$ & $556.27 \pm 114.83 \mathrm{bc}$ & $29.25 \pm 3.14 \mathrm{ab}$ & $24.35 \pm 3.16 b$ & $17.08 \pm 2.46 \mathrm{a}$ & $9.20 \pm 1.84 b$ \\
\hline $\mathrm{RB}$ & $29.33 \pm 4.12 \mathrm{~b}$ & $513.31 \pm 129.55 \mathrm{ab}$ & $28.36 \pm 3.86 \mathrm{ab}$ & $23.39 \pm 3.43 \mathrm{ab}$ & $15.92 \pm 1.90 \mathrm{a}$ & $8.83 \pm 2.38 b$ \\
\hline $\mathrm{R}$ & $31.33 \pm 9.41 \mathrm{~b}$ & $588.58 \pm 121.20 \mathrm{c}$ & $30.10 \pm 3.95 b$ & $24.95 \pm 2.60 \mathrm{~b}$ & $17.21 \pm 3.27 \mathrm{a}$ & $10.50 \pm 2.54 c$ \\
\hline $\mathrm{Fl}^{1}$ & $30.44 \pm 5.83 b^{2}$ & $474.57 \pm 56.24 \mathrm{a}$ & $27.88 \pm 1.77 \mathrm{a}$ & $21.92 \pm 1.84 \mathrm{a}$ & $16.02 \pm 1.84 \mathrm{a}$ & $7.39 \pm 1.48 \mathrm{a}$ \\
\hline \multicolumn{7}{|c|}{ BA concentrations $(\mu \mathrm{M})$} \\
\hline 1 & $27.67 \pm 5.25 \mathrm{a}$ & $563.09 \pm 135.72 \mathrm{a}$ & $29.19 \pm 3.53 \mathrm{a}$ & $24.78 \pm 3.53 \mathrm{~b}$ & $17.40 \pm 2.26 \mathrm{~b}$ & $9.62 \pm 2.20 \mathrm{~b}$ \\
\hline 2.5 & $27.17 \pm 6.06 \mathrm{a}$ & $511.21 \pm 76.70 \mathrm{a}$ & $28.59 \pm 2.41 \mathrm{a}$ & $23.06 \pm 2.42 \mathrm{a}$ & $15.60 \pm 1.79 \mathrm{a}$ & $8.13 \pm 1.50 a$ \\
\hline 5 & $30.00 \pm 9.62 \mathrm{a}$ & $525.25 \pm 123.92 \mathrm{a}$ & $28.92 \pm 4.00 \mathrm{a}$ & $23.11 \pm 2.72 \mathrm{a}$ & $16.68 \pm 2.94 \mathrm{ab}$ & $9.19 \pm 2.94 b$ \\
\hline
\end{tabular}

${ }^{1} \mathrm{~B}-100 \%$ blue LED (430 nm); RB—combination of red (70\%) and blue (30\%) LED; R-100\% red LED (670 nm);

Fl-control, fluorescence Philips TK-D 36W/54 lamps. ${ }^{2}$ Means \pm standard deviations within a column followed by the same letter are not significantly different according to Duncan's multiple range test at $p \leq 0.05$.

The lowest concentration of BA $(1 \mu \mathrm{M})$ in the growth medium triggered the development of wider stomata more than higher BA levels. The length and width of the pore were the smallest in the medium containing $2.5 \mu \mathrm{M}$ BA. Medium cytokinin content had no statistically important effect on the number, area and length of the stomata.

In plants cultivated under 100\% red light, the number and area (length and width) of stomata increased along with growing concentration of BA in the medium. The highest stomata frequency was detected in plants under $100 \%$ red light grown in the medium with $5 \mu \mathrm{M}$ BA (Table S1). These stomata 
had also the largest surface area of all the other combinations. An inverse relationship was noted under $100 \%$ blue light, where increasing BA concentration caused the surface area of the stomata to decrease.
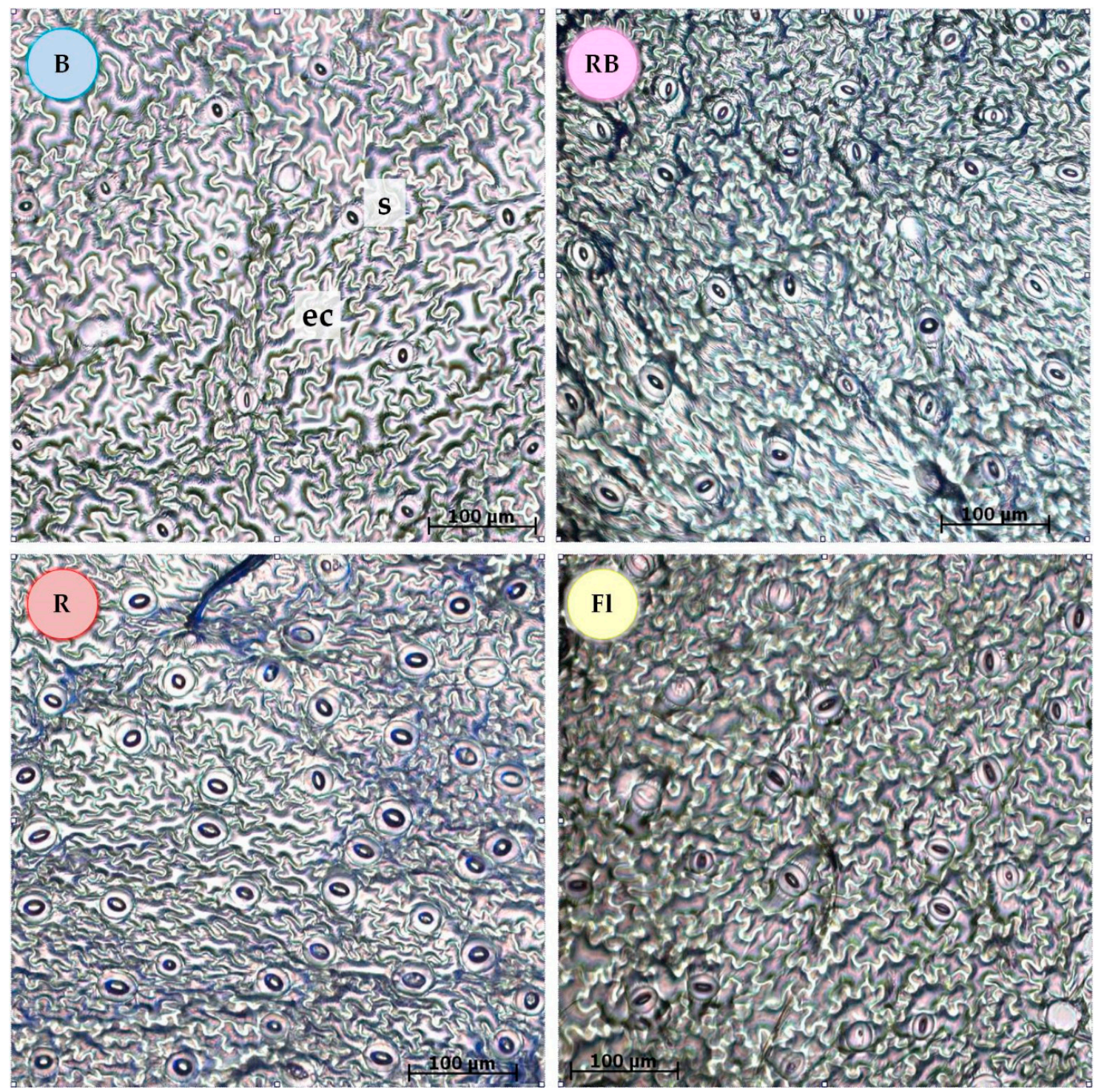

Figure 2. Abaxial side of a leaf blade in vitro with stomata after 6 weeks of shoot multiplication in the medium with $5 \mu \mathrm{M} \mathrm{BA}$, under different light qualities. B-100\% blue light-emitting diode (LED); RB - mixed red and blue LED (7:3); R-100\% red LED; Fl—control, white fluorescent light; visible area, $500 \times 500 \mu \mathrm{m}$; ec-epidermal cells; s—stomata; scale bar, $100 \mu \mathrm{m}$.

\subsection{Leaf Anatomical Structure}

Figures 3 and 4 and Table S2 show the effects of light quality on the anatomical parameters of the leaves. Plants multiplied under 100\% blue light and a mixture of blue and red light (7:3 RB) developed the thickest leaf blades, while those exposed to RB LED and control (Fl) light had the thickest petioles. The thinnest epidermis, both in the leaf blades and petioles, was detected in the leaves developing under RB light. In the case of petioles, thin epidermis was also seen under $100 \%$ red light. Research has shown that the spongy mesophyll is the most important factor determining total leaf thickness. The palisade mesophyll was the thickest in the leaves exposed to B and RB light, while the spongy mesophyll layer was the widest under 100\% blue light. 

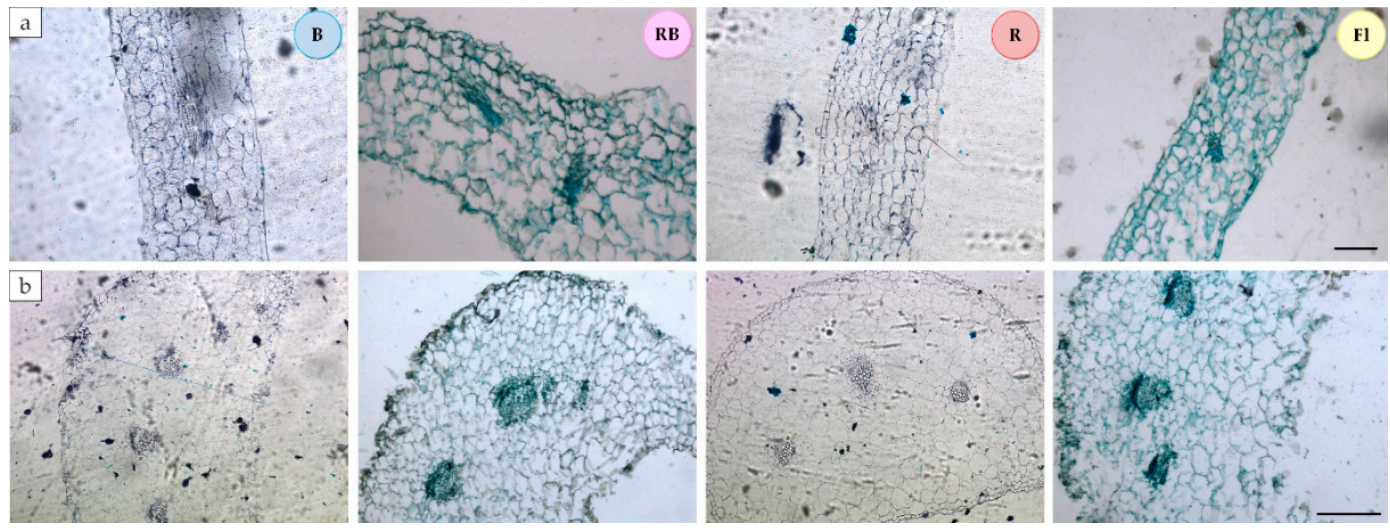

Figure 3. Anatomical structure of gerbera leaves grown under different light conditions and in the medium containing $5 \mu \mathrm{M}$ BA; (a) leaf blade cross-section, (b) petiole cross-section; B-100\% blue LED, RB — mixed red and blue LED (7:3); R-100\% red LED; Fl—control, white fluorescent lamp; scale bar, $100 \mu \mathrm{m}$.

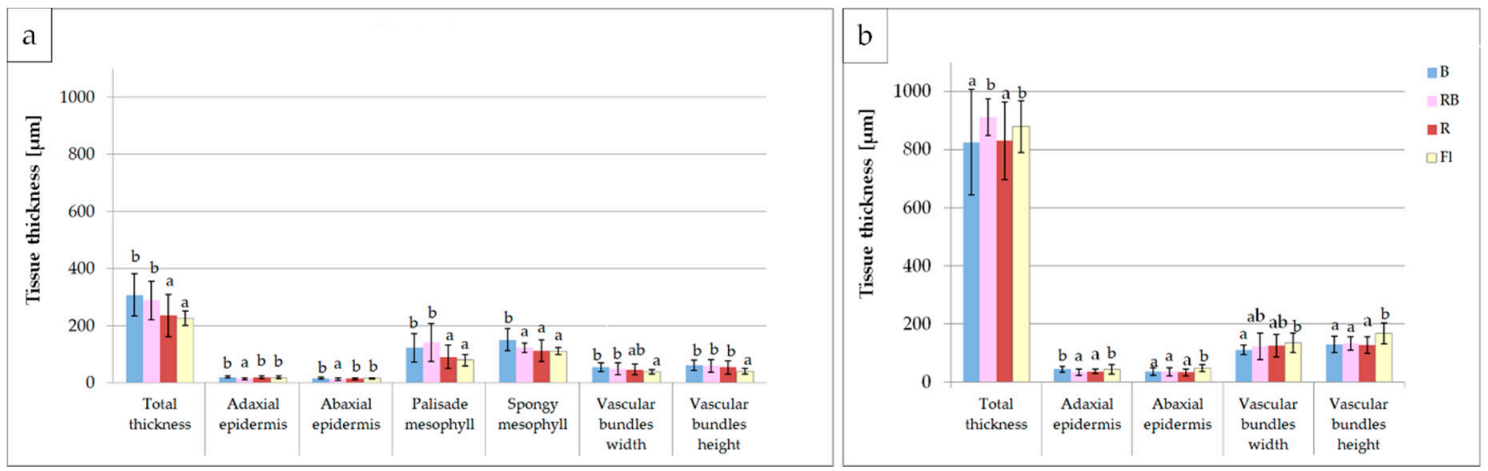

Figure 4. Characteristics of gerbera leaf anatomy: (a) blade and (b) petiole structure after 6 weeks of in vitro cultivation of shoots depending on the quality of light; B-100\% blue LED; RB-mixed red and blue LED (7:3); R-100\% red LED; Fl—control, white fluorescent lamp; tissue thickness in $\mu \mathrm{m}$; mean values are presented with standard deviation bars; columns followed by the same letter are not significantly different according to Duncan's multiple range test at $p \leq 0.05$.

The cross-section of the leaf blade vascular bundles was usually two times smaller than that of the petioles. We also noticed that in plants growing under LED (all combinations: R, B and RB), the vascular bundles in the leaf blades were larger than those under the control light ( $\mathrm{Fl})$. A reverse relationship was detected in the petioles, where the largest vascular bundles developed under the control light (Fl).

Increasing BA concentration in the medium resulted in thickening the leaf blades (Figure 5 and Table S3), a pattern that was not confirmed in the petioles. Leaf blades of shoots propagated in the medium supplemented with $5 \mu \mathrm{M}$ BA developed palisades and spongy mesophylls of the greatest thickness and vascular bundles with the largest cross-section as compared with lower BA concentrations (1 and $2.5 \mu \mathrm{M}$ ). 

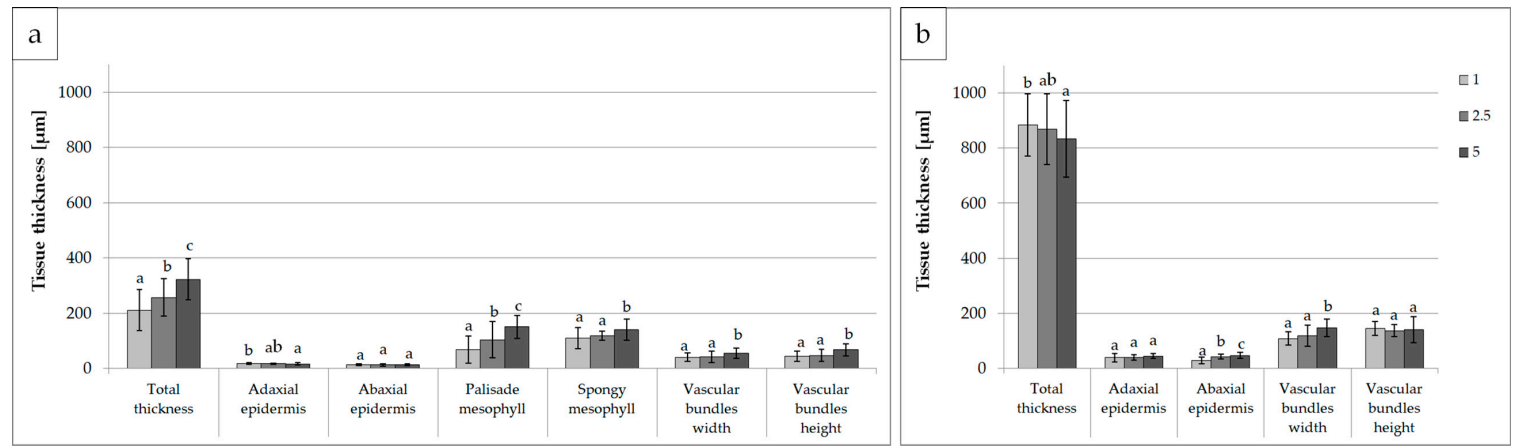

Figure 5. Characteristics of gerbera leaf anatomy: (a) blade and (b) petiole structure after 6 weeks of in vitro cultivation of shoots depending on BA concentration in the medium $-1,2.5$ or $5 \mu \mathrm{M}$; tissue thickness in $\mu \mathrm{m}$; mean values are presented with standard deviation bars; columns followed by the same letter are not significantly different according to Duncan's multiple range test at $p \leq 0.05$.

Detailed analysis (Tables S4 and S5) revealed the thickest leaf blades in the plants multiplied under blue light $(100 \%$ B) in the presence of $5 \mu \mathrm{M}$ BA (Table S4). For each tested light spectrum, the highest concentration of BA $(5 \mu \mathrm{M})$ increased the thickness of the leaf blade, while control fluorescent light and $1 \mu \mathrm{M}$ BA reduced the blade volume. Again, the pattern observed in the leaf blades was not confirmed in the petioles. The thickest leaves developed at $2.5 \mu \mathrm{M} \mathrm{BA}$, except for $100 \%$ blue light.

\subsection{Photosynthetic Pigment Content}

Different light quality affected the level of photosynthetic pigments in gerbera leaves. The leaves of shoots multiplied under 100\% red light, and a mixture (7:3) of red and blue light featured the highest content of photosynthetically active pigments (chlorophyll $a, b$ and carotenoids) (Figure 6, Table S6).

In addition, apart from a strong positive correlation between synthesis of chlorophyll $a$ and $b$ and a moderate positive correlation between the levels of chlorophyll $a$ and carotenoids, we detected a weak negative correlation between chlorophyll $a$ and $b$ levels and thickness of the spongy mesophyll of leaf blades (Table 3).

Table 3. Map of the correlations between the level of photosynthetic pigments and other investigated parameters of gerbera leaves grown under different qualities of LED light and in the media with different concentrations of BA.

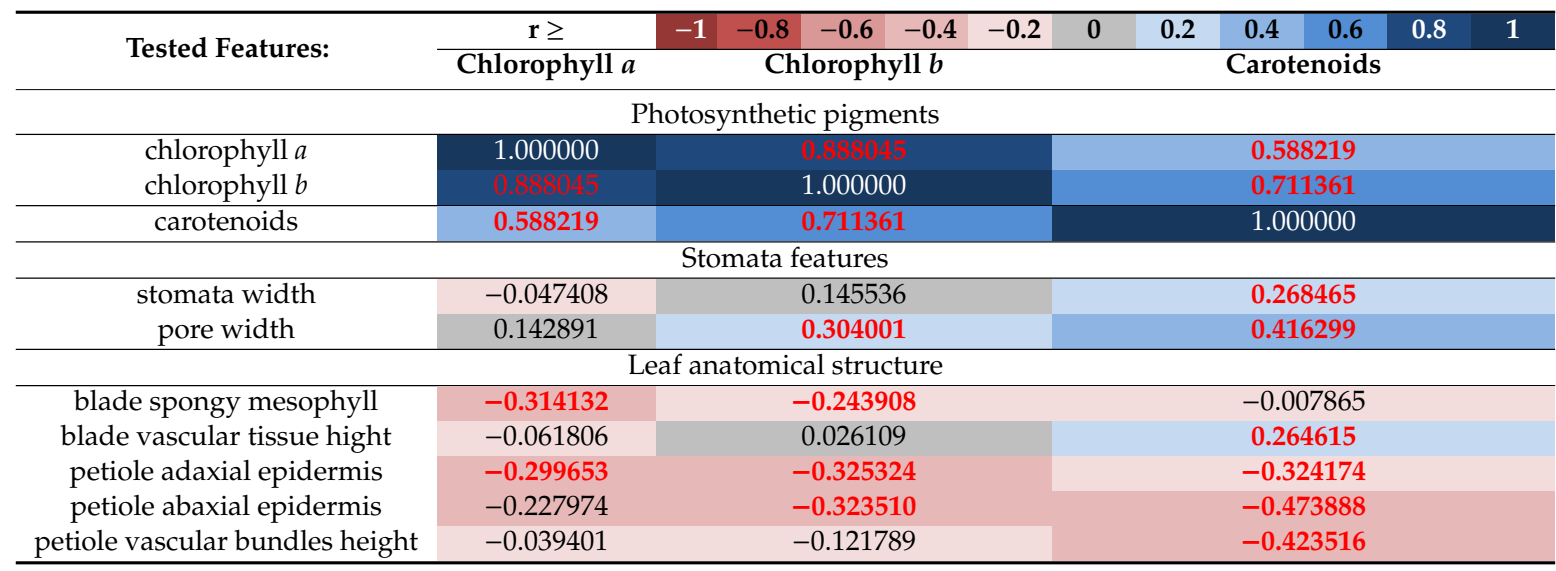

Colors show the strength of correlation. Red indicates the presence of correlation; $p \leq 0.05$. 

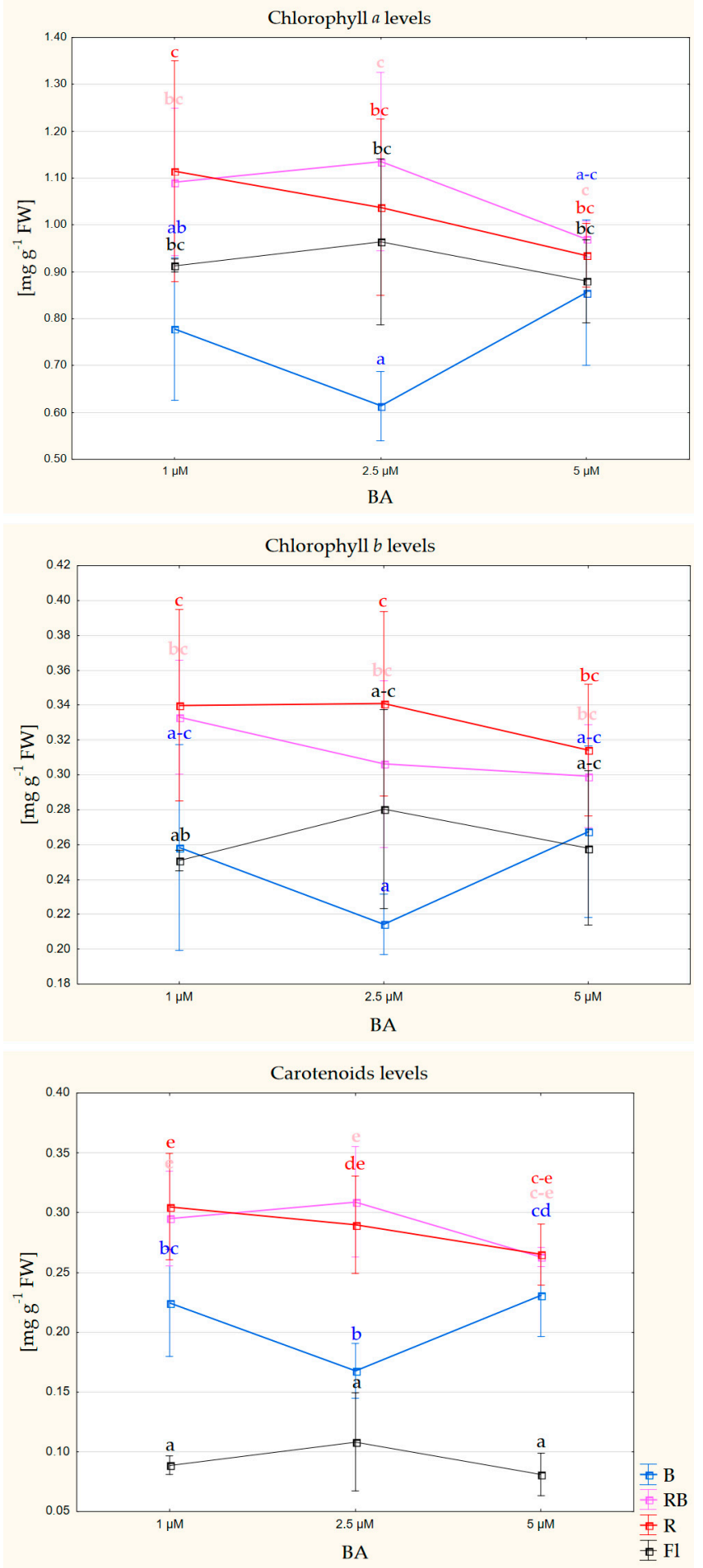

Figure 6. The level of photosynthetic pigments in gerbera leaves multiplied for 6 weeks under different quality of light (B-100\% blue LED; RB — mixed red and blue LED (7:3); R—100\% red LED; Fl—control, white fluorescent lamp) and different concentrations of BA in the medium; mean values are presented with standard deviation bars; columns followed by the same letter are not significantly different according to Duncan's multiple range test at $p \leq 0.05$.

\section{Discussion}

Our study demonstrated a complex pattern of leaf responses to different light conditions in an in vitro culture. The responses involved morphological, anatomical (tissue and cell structure) and 
biochemical (e.g., photosynthetic pigment content) changes [11,12,18-21]. By setting specific light conditions for a given species and development stage in an in vitro culture, it is possible to modify the quantitative and qualitative parameters of plants, such as the number of new shoots, plant height, shape, color and active substance content and, particularly, the features and parameters of the leaves. After rooting the shoots multiplied in vitro, the physiological condition and proper structure of the leaves should ensure efficient plant adaptation to the environmental conditions and its further proper growth and development. Poor survival rates during acclimatization are often associated with inappropriate external conditions during micropropagation. This may cause poor morphological and anatomical development of the leaves, malfunctioning of stomata, excessive water loss and poor photosynthetic capacity [22].

The stomata allow the plant to perform gas exchange. The greater their number, the more effective and faster gas exchange is. Depending on the environmental conditions, the stomata vary not only in terms of their number but also their size, shape and degree of opening [23]. All these features affect stomatal conductance to $\mathrm{CO}_{2}$ diffusion [24]. In in vitro conditions, stomata are often round and wide open [23]. It is also known that intensely-growing plants develop a smaller number of larger stomata $[25,26]$. This was not confirmed in our study as under RB light, where gerbera shoot multiplication rate was the highest [11], the stomata frequency was not lower than under light combinations providing a lower multiplication rate. Similarly, stomata in the leaves developed under RB light did not have a larger area. Some authors indicate a negative correlation between stomata frequency and stomata size [24,25]. In our study, this correlation was not confirmed for $100 \%$ red light. Gerbera shoots grown under $100 \%$ red LED light had an increased surface area, and those in the medium with $5 \mu \mathrm{M}$ BA had the highest stomata frequency on the abaxial side of the leaf blade. Contrary to that, $100 \%$ blue light was conducive to larger and less numerous stomata. Similar results were published for Alternanthera brasiliana [27], where blue light decreased the stomata frequency on the abaxial side of the leaf blade. Weng et al. [8] tested stomatal frequency under different R/B ratios for lettuce grown in the controlled environment of a hydroponic system. They found the greatest stomata frequency in lettuce cultivated under 100\% red LED light, both on the abaxial and adaxial leaf surfaces. Kim et al. [25] reported the highest stomata frequency in Chrysanthemum exposed to LED lights: blue + far red and $100 \%$ red. This was confirmed in our study, as the presence of red light in the spectrum during multiplication increased the stomata frequency in gerbera leaves. This suggests the necessity of including red light in the light spectrum employed during gerbera micropropagation. The greater number of stomata will probably improve gas exchange and intensify photosynthesis and, thus, facilitate acclimatization. Leaves developed under $100 \% \mathrm{R}$, especially in the medium supplemented with $5 \mu \mathrm{M}$ BA, had stomata with a larger area. The increased surface of the stomata was also observed in plants grown under blue LED light $(100 \%$ B). Heo et al. [28] found the smallest stomata in sage leaves multiplied under blue LED light, but the quality of light had no effect on the size of stomata in marigold. In our study, the fluorescent light reduced the surface area of stomata as compared to light emitted by all LED combinations. Contrary to that, Kim et al. [25] reported the same size of stomata in chrysanthemum leaves exposed to LED (R or B) lamps and fluorescent lamps. The mixed spectrum of $\mathrm{RB}$ resulted in stomata of a larger diameter. The size of the stomata is important for the entire plant performance, as their geometry, together with limitations regarding the number of stomata per leaf area, mean that leaves with large stomata usually show lower maximum capacity of $\mathrm{CO}_{2}$ absorption. Smaller stomata might be beneficial as they may be capable of a faster response to environmental stimuli than the larger ones. However, this feature seems species-specific [29]. In all probability, the size of stomata during shoot multiplication and rooting does not translate into their size at later stages of clonal propagation. This was confirmed by our observation that subsequent rooting of shoots under this light in acclimatized plants resulted in the formation of stomata with the smallest surface area [12]. Despite some literature reports on the relationship between stomata parameters and light quality, plant response is, in fact, highly specific. 
The anatomical structure of leaves grown under fluorescent lamps traditionally used in in vitro cultures is different than that of plants growing in vitro under LED light [30,31], which indicates another advantage of energy-saving LEDs that do not change the leaf anatomy, as compared with plants exposed to traditional light conditions. Studies on micropropagation of gerbera revealed that vascular bundles in the leaf blades treated with fluorescent light had a smaller diameter than those in the leaves exposed to different LED light compositions. This enlarged diameter might be deemed positive, as it facilitates the downstream transport of assimilates and upstream transport of water and minerals. Additionally, the vascular bundles enhance plant robustness. There is no available information on the effects of light quality on the size of vascular bundles, but Fryer et al. [32,33] demonstrated their different diameters in Arabidopsis thaliana treated with lights of different intensities. Differences in the thickness of leaf blades are usually due to the content share of mesophyll affected by the applied light spectrum [30,31], which has the greatest impact during leaf expansion [34]. Mesophyll structure is related to the specific light spectrum used in in vitro culture. Palisade mesophyll allows for better penetration of light inside the chloroplasts, while spongy mesophyll enhances light capture by scattering light [27]. Leaf blades of gerbera shoots developed under LED light that contained blue spectrum (100\% B or RB: $7 / 3$ ) produced thicker palisade and spongy mesophyll. The thinnest leaves were observed in plants developed under light containing only the red LED spectrum $(100 \% \mathrm{R})$. These findings were confirmed in a study by Macedo et al. [27], in which blue LED light increased the thickness of palisade vs. spongy mesophyll in Alternanthera brasiliana L. Red light reduced the thickness of both layers, with stronger suppression of the spongy mesophyll. In a traditional autotrophic cultivation, this may be due to lowered photosynthetic activity, as indicated by different studies [35-38]. Development of thinner leaf blades is also attributed to enhanced sharing of red light in relation to far red [39-41] but may be also due to reduced sharing of blue light in the applied light spectrum [42]. The lower thickness of leaf blades noted under red light can be explained as the plant response to radiation stress [43], and perceived as a protective mechanism manifested in the reduced number and size of cells, as determined for Pisum sativum L. [44], or as an adaptation of leaf structure to radiation, as observed in Cucumis sativus L., Phaseolus vulgaris L. and Raphanus sativus L. [45].

During micropropagation, the thickness of the epidermis depends on the quality of light and the content of growth regulators in the medium. By controlling these external conditions, it is possible to balance the negative effects of high humidity inside the culture vessel on epidermal thinning. Mixed LED RB light, applied during multiplication of axillary shoots of gerbera, reduced the thickness of both the lower and upper epidermis of leaf blades, which is probably undesirable. However, simultaneous reduction in BA to 1 and $2.5 \mu \mathrm{M}$ under this light increased the thickness of the upper epidermis. Fukuda et al. [46] demonstrated the effects of light quality on the elongation growth of epidermal cells. Epinasty in Geranium leaves was controlled by blue light, which stimulated elongation growth of adaxial epidermis cells.

From a practical perspective, it is essential to determine the external conditions of the culture to obtain the best possible parameters of leaves at subsequent stages of in vitro reproduction. Gerbera leaf blades were the thickest when the LED spectrum contained blue light (B, RB), and the thickest petioles developed under mixed RB or control fluorescent light. Therefore, to achieve the greatest thickness of leaf blades and petioles, it is recommended to use RB LED light. The effects of light during micropropagation can be altered by modifying cytokinin concentration in the medium. Increasing concentrations of BA in the medium $(1,2.5$ and $5 \mu \mathrm{M})$ positively affected thickness of leaf blades and negatively affected that of leaf petioles. In conclusion, axillary shoots of gerbera grew leaves (blades and petioles) of the best quality under LED RB (7:3) in the medium containing $2.5 \mu \mathrm{M}$ BA. Earlier studies demonstrated the highest shoot multiplication rate under these light conditions (RB) [11].

The spectral quality of light during plant growth and development affects the synthesis and degradation of photosynthetic pigments, which is related to plant adaptability [47]. Studies in different plant species indicated positive effects of LED emitted light on the synthesis of photosynthetic pigments. In gerbera cv. Big Apple and Dura, these effects were the most pronounced under RB LED [11,12], and 
in cv. Rui Kou, under 100\% R and 100\% B [48]. Additionally, in these experiments, gerbera reproduced under LED containing red light spectrum (R and RB) had increased content of chlorophyll $a, b$ and carotenoids. A higher level of photosynthetic pigments in the leaves of in vitro cultivated plants will facilitate their acclimatization and the switch to autotrophy.

The correlation between the levels of chlorophyll $a$ and $b$ and thickness of spongy mesophyll is probably associated with localization of the pigments. They are located in the chloroplasts of spongy mesophyll responsible for capturing light, while vertically elongated palisade cells allow for deeper penetration of light inside the leaf [2]. This correlation is negative-in plants with a thicker layer of spongy mesophyll, synthesis of chlorophyll $a$ and $b$ also does not increase. It can be assumed that the increasing thickness of the spongy mesophyll would not translate into a higher level of photosynthetic pigments.

\section{Conclusions}

Evaluation of structural changes in a tissue or organ formed in vitro is of great value in discovering the actual efficiency of organogenesis and the functioning of a new organ. Leaves show high phenotypic plasticity in response to light conditions. Our study demonstrated that a mixture of blue and red light provided by LED improved leaf quality during multiplication of gerbera shoots. Leaves of the shoots multiplied under these conditions had more and greater stomata than under fluorescent light, and vascular bundles were of a greater diameter. The leaves also had a thicker palisade and spongy mesophyll as blue light enhanced their development. In in vitro conditions, the epidermal layers were thin but can be strengthened by lowering the cytokinin level. This light composition also provided the highest content of photosynthetic pigments.

Supplementary Materials: The following are available online at http://www.mdpi.com/2073-4395/10/11/1832/s1, Table S1: Characteristics of the stomata in gerbera leaves after 6 weeks of in vitro cultivation of shoots depending on the quality of light and the concentration of BA in the medium - two-factor ANOVA analysis., Table S2: Data for characteristics of gerbera leaf anatomical structure after 6 weeks of in vitro cultivation of shoots depending on the quality of light, tissue thickness in $\mu \mathrm{m}$., Table S3: Data for characteristics of gerbera leaf anatomical structure after 6 weeks of in vitro cultivation of shoots depending on BA concentration in the medium, tissue thickness in $\mu \mathrm{m}$., Table S4: Characteristics of gerbera leaf blade anatomical structure after 6 weeks of in vitro cultivation of shoots depending on the quality of light and BA concentration in the medium-two-factor ANOVA analysis; tissue thickness in $\mu \mathrm{m}$., Table S5: Characteristics of gerbera petiole anatomical structure after 6 weeks of in vitro cultivation of shoots depending on the quality of light and BA concentration in the medium - two-factor ANOVA analysis; tissue thickness in $\mu \mathrm{m}$., Table S6: The level of photosynthetic pigments in gerbera leaves multiplied for 6 weeks under different quality of light and different concentrations of BA in the medium.

Author Contributions: Conceptualization, B.P.; methodology, M.C. and B.P.; software, M.C.; validation, B.P.; formal analysis, M.C. and B.P.; investigation, M.C.; resources, M.C.; data curation, M.C.; writing-original draft preparation, M.C.; writing-review and editing, M.C. and B.P.; visualization, M.C.; supervision, B.P.; project administration, M.C. and B.P.; funding acquisition, M.C. All authors have read and agreed to the final version of the manuscript.

Funding: This research was funded by the NATIONAL SCIENCE CENTER (POLAND), grant number 2017/27/N/NZ9/00965.

Acknowledgments: Special thanks to Katarzyna Kiełkowicz for technical help in result collecting.

Conflicts of Interest: The authors declare no conflict of interest.

\section{References}

1. Nevo, E.; Pavlíek, T.; Beharv, A.; Bolshakova, M.A.; Martyn, G.I.; Musatenko, L.I.; Sytnikl, K.M. Drought and light anatomical adaptive leaf strategies in three woody species caused by microclimatic selection at "Evolution Canyon", Israel. Isr. J. Plant Sci. 2000, 48, 33-46. [CrossRef]

2. Johnson, D.M.; Smith, W.K.; Vogelmann, T.C.; Brodersen, C.R. Leaf architecture and direction of incident light influence mesophyll fluorescence profiles. Am. J. Bot. 2005, 92, 1425-1431. [CrossRef]

3. Rezende, R.K.S.; Paiva, L.V.; Paiva, R.; Chalfun Júnior, A.; Torga, P.P.; Mauro de Castro, E. Capitulum organogenesis and anatomical characterization of Gerbera jamesonii Adlan leaves. Ciência e Agrotecnologia 2008, 32, 821-827. [CrossRef] 
4. Xiao, Y.; Tholen, D.; Zhu, X.G. The influence of leaf anatomy on the internal light environment and photosynthetic electron transport rate: Exploration with a new leaf ray tracing model. J. Exp. Bot. 2016, 67, 6021-6035. [CrossRef] [PubMed]

5. Zeiger, E. Blue Light and stomatal function. In Blue Light Effects in Biological Systems; Springer: Berlin/Heidelberg, Germany, 1984; pp. 484-494. ISBN 978-3-642-69767-8.

6. Hetherington, A.M.; Woodward, F.I. The role of stomata in sensing and driving environmental change. Nature 2003, 424, 901-908. [CrossRef] [PubMed]

7. Inoue, S.I.; Kinoshita, T. Blue light regulation of stomatal opening and the plasma membrane $\mathrm{H}^{+}$-ATPase. Plant Physiol. 2017, 174, 531-538. [CrossRef]

8. Wang, J.; Lu, W.; Tong, Y.; Yang, Q. Leaf morphology, photosynthetic performance, chlorophyll fluorescence, stomatal development of lettuce (Lactuca sativa L.) exposed to different ratios of red light to blue light. Front. Plant Sci. 2016, 7, 1-10. [CrossRef]

9. Hronková, M.; Wiesnerová, D.; Šimková, M.;Skůpa, P.; Dewitte, W.; Vráblová, M.; Zažímalová, E.; Šantrůček, J. Light-induced STOMAGEN-mediated stomatal development in Arabidopsis leaves. J. Exp. Bot. 2015, 66, 4621-4630. [CrossRef]

10. Stefanova, M.A.; Koleva, D.P.; Ganeva, T.G.; Dimitrova, M.A. Effect of plant growth regulators on the regeneration of in vitro-propagated Lamium album L. plants. J. Pharm. 2011, 4, 1982-1985.

11. Pawłowska, B.; Żupnik, M.; Szewczyk-Taranek, B.; Cioć, M. Impact of LED light sources on morphogenesis and levels of photosynthetic pigments in Gerbera jamesonii grown in vitro. Hortic. Environ. Biotechnol. 2018, 59, 115-123. [CrossRef]

12. Pawłowska, B.; Cioć, M.; Prokopiuk, B. How LED light rooting in vitro affected Gerbera acclimatization efficiency. Acta Hortic. 2018, 583-590. [CrossRef]

13. Cioć, M.; Kalisz, A.; Żupnik, M.; Pawłowska, B. Different LED light intensities and 6-benzyladenine concentrations in relation to shoot development, leaf architecture, and photosynthetic pigments of Gerbera jamesonii Bolus in vitro. Agronomy 2019, 9, 358. [CrossRef]

14. Murashige, T.; Skoog, F. A revised medium for rapid growth and bio assays with tabacco tissue cultures. Physiol. Plant. 1962, 15, 473-497. [CrossRef]

15. Li, H.; Xu, Z.; Tang, C. Effect of light-emitting diodes on growth and morphogenesis of upland cotton (Gossypium hirsutum L.) plantlets in vitro. Plant Cell Tissue Organ Cult. 2010, 103, 155-163. [CrossRef]

16. Filutowicz, A.; Kużdowicz, A. Mikrotechnika Roślinna; PWRiL: Warszawa, Poland, 1951.

17. Lichtenthaler, H.K.; Buschmann, C. Chlorophylls and carotenoids: Measurement and characterization by UV-VIS spectroscopy. Curr. Protoc. Food Anal. Chem. 2001, 171-178. [CrossRef]

18. Sæbø, A.; Krekling, T.; Appelgren, M. Light quality affects photosynthesis and leaf anatomy of birch plantlets in vitro. Plant Cell Tissue Organ Cult. 1995, 41, 177-185. [CrossRef]

19. Bello-Bello, J.J.; Martínez-Estrada, E.; Caamal-Velázquez, J.H.; Morales-Ramos, V. Effect of LED light quality on in vitro shoot proliferation and growth of vanilla (Vanilla planifolia Andrews). Afr. J. Biotechnol. 2016, 15, 272-277. [CrossRef]

20. Ramírez-Mosqueda, M.A.; Iglesias-Andreu, L.G.; Bautista-Aguilar, J.R. The effect of light quality on growth and development of in vitro plantlet of Stevia rebaudiana Bertoni. Sugar Tech 2017, 19, 331-336. [CrossRef]

21. Chen, L.; Zhang, K.; Gong, X.; Wang, H.; Gao, Y.; Wang, X.; Zeng, Z.; Hu, Y. Effects of different LEDs light spectrum on the growth, leaf anatomy, and chloroplast ultrastructure of potato plantlets in vitro and minituber production after transplanting in the greenhouse. J. Integr. Agric. 2020, 19, 108-119. [CrossRef]

22. Zobayed, S.M.A.; Afreen-Zobayed, F.; Kubota, C.; Kozai, T. Stomatal characteristics and leaf anatomy of potato plantlets cultured in vitro under photoautotrophic and photomixotrophic conditions. Vitr. Cell. Dev. Biol. Plant 1999, 35, 183-188. [CrossRef]

23. Tichá, I.; Radochová, B.; Kadleček, P. Stomatal morphology during acclimatization of tobacco plantlets to $e x$ vitro conditions. Biol. Plant. 1999, 42, 469-474. [CrossRef]

24. Camargo, M.A.B.; Marenco, R.A. Density, size and distribution of stomata in 35 rainforest tree species in Central Amazonia. Acta Amaz. 2011, 41, 205-212. [CrossRef]

25. Kim, S.J.; Hahn, E.J.; Heo, J.W.; Paek, K.Y. Effects of LEDs on net photosynthetic rate, growth and leaf stomata of chrysanthemum plantlets in vitro. Sci. Hortic. (Amst.) 2004, 101, 143-151. [CrossRef]

26. Gupta, S.; Jatothu, B. Fundamentals and applications of light-emitting diodes (LEDs) in in vitro plant growth and morphogenesis. Plant Biotechnol. Rep. 2013, 7, 211-220. [CrossRef] 
27. Macedo, A.F.; Leal-Costa, M.V.; Tavares, E.S.; Lage, C.L.S.; Esquibel, M.A. The effect of light quality on leaf production and development of in vitro-cultured plants of Alternanthera brasiliana Kuntze. Environ. Exp. Bot. 2011, 70, 43-50. [CrossRef]

28. Heo, J.; Lee, C.; Chakrabarty, D.; Paek, K. Growth responses of marigold and salvia bedding plants as affected by monochromic or mixture radiation provided by a light-emitting diode (LED). Plant Growth Regul. 2002, 38, 225-230. [CrossRef]

29. Jordan, G.J.; Carpenter, R.J.; Koutoulis, A.; Price, A.; Brodribb, T.J. Environmental adaptation in stomatal size independent of the effects of genome size. New Phytol. 2015, 205, 608-617. [CrossRef]

30. Aranda, I.; Pardo, F.; Gil, L.; Pardos, J.A. Anatomical basis of the change in leaf mass per area and nitrogen investment with relative irradiance within the canopy of eight temperate tree species. Acta Oecologica 2004, 25, 187-195. [CrossRef]

31. Gonçalves, B.; Correia, C.M.; Silva, A.P.; Bacelar, E.A.; Santos, A.; Moutinho-Pereira, J.M. Leaf structure and function of sweet cherry tree (Prunus avium L.) cultivars with open and dense canopies. Sci. Hortic. (Amst.) 2008, 116, 381-387. [CrossRef]

32. Fryer, M.J.; Oxborough, K.; Mullineaux, P.M.; Baker, N.R. Imaging of photo-oxidative stress responses in leaves. J. Exp. Bot. 2002, 53, 1249-1254. [CrossRef]

33. Fryer, M.J.; Ball, L.; Oxborough, K.; Karpinski, S.; Mullineaux, P.M.; Baker, N.R. Control of Ascorbate Peroxidase 2 expression by hydrogen peroxide and leaf water status during excess light stress reveals a functional organisation of Arabidopsis leaves. Plant J. 2003, 33, 691-705. [CrossRef] [PubMed]

34. Schuerger, A.C.; Brown, C.S.; Stryjewski, E.C. Anatomical features of pepper plants (Capsicum annuum L.) grown under red light-emitting diodes supplemented with blue or far-red light. Ann. Bot. 1997, 79, $273-282$. [CrossRef] [PubMed]

35. Thompson, W.A.; Kriedemann, P.E.; Craig, I.E. Photosynthetic response to light and nutrients in sun-tolerant and shade-tolerant rainforest trees. I. Growth, leaf anatomy and nutrient content. Aust. J. Plant Physiol. 1992, 19, 1-18. [CrossRef]

36. Strauss-Debenedetti, S.; Berlyn, G.P. Leaf anatomical responses to light in five tropical Moraceae of different successional status. Am. J. Bot. 1994, 81, 1582-1591. [CrossRef]

37. Terashima, I.; Miyazawa, S.I.; Hanba, Y.T. Why are sun leaves thicker than shade leaves?-Consideration based on analyses of $\mathrm{CO}_{2}$ diffusion in the leaf. J. Plant Res. 2001, 114, 93-105. [CrossRef]

38. Li, Z.; Zhang, S.; Hu, H.; Li, D. Photosynthetic performance along a light gradient as related to leaf characteristics of a naturally occurring Cypripedium flavum. J. Plant Res. 2008, 121, 559-569. [CrossRef]

39. Kasperbauer, M.J.; Peaslee, D.E. Morphology and photosynthetic efficiency of tobacco leaves that received end-of-day red and far red light during development. Plant Physiol. 1973, 52, 440-442. [CrossRef]

40. Boardman, N.K. Comparative photosynthesis of sun and shade plants. Annu. Rev. Plant Physiol. 1977, 28, 355-377. [CrossRef]

41. Barreiro, R.; Guiamét, J.J.; Beltrano, J.; Montaldi, E.R. Regulation of the photosynthetic capacity of primary bean leaves by the red: Far-red ratio and photosynthetic photon flux density of incident light. Physiol. Plant. 1992, 85, 97-101. [CrossRef]

42. Pushnik, J.C.; Miller, G.W.; Jolley, V.D.; Brown, J.C.; Davis, T.D.; Barnes, A.M. Influences of ultra-violet (UV)-blue light radiation on the growth of cotton. II. Photosynthesis, leaf anatomy, and iron reduction. J. Plant Nutr. 1987, 10, 2283-2297. [CrossRef]

43. Wellman, E. UV radiation in photomorphogenisis. In Encyclopedia of Plant Physiology: New Series. Photomorphogenesis; Shropshire, W., Mohr, H., Eds.; Springer: Berlin/Heidelberg, Germany, 1983.

44. Gonzalez, R.M.; Efsted, R.; Wellburn, A.R.; Paul, N.D. Non-photosynthetic mechanisms of growth reduction in pea (Pisum sativum L.) exposed to UV-B radiation. Plant Cell Environ. 1998, 21, 23-32. [CrossRef]

45. Tevini, M.; Thoma, U.; Iwanzik, W. Effects of UV-B radiation on germination, seedling growth, leaf anatomy, and pigments of some crop plants. Zeitschrift für Pflanzenphysiologie 1983, 109, 435-448. [CrossRef]

46. Fukuda, N.; Fujita, M.; Ohta, Y.; Sase, S.; Nishimura, S.; Ezura, H. Directional blue light irradiation triggers epidermal cell elongation of abaxial side resulting in inhibition of leaf epinasty in geranium under red light condition. Sci. Hortic. (Amst.) 2008, 115, 176-182. [CrossRef] 
47. Zervoudakis, G.; Salahas, G.; Kaspiris, G.; Konstantopoulou, E. Influence of light intensity on growth and physiological characteristics of common sage (Salvia officinalis L.). Braz. Arch. Biol. Technol. 2012, 55, 89-95. [CrossRef]

48. Wang, Z.; Li, G.; He, S.; Teixeira da Silva, J.A.; Tanaka, M. Effect of cold cathode fluorescent lamps on growth of Gerbera jamesonii plantlets in vitro. Sci. Hortic. (Amst.) 2011, 130, 482-484. [CrossRef]

Publisher's Note: MDPI stays neutral with regard to jurisdictional claims in published maps and institutional affiliations.

(C) 2020 by the authors. Licensee MDPI, Basel, Switzerland. This article is an open access article distributed under the terms and conditions of the Creative Commons Attribution (CC BY) license (http://creativecommons.org/licenses/by/4.0/). 